\title{
Public Issues Education and Extension Practice in Nigeria
}

\author{
B.F. Umar \\ Department of Agricultural Economics and Extension \\ Kebbi State University of Science and Technology, Aliero, \\ E-mail: bfumar@yahoo.com ; Mobile: +2348035816472
}

\begin{abstract}
This paper advocates that public issues education (PIE) and conflict management are new societal concerns extension professionals in Nigeria should tackle. The paper believes that incorporating PIE into policy making will allow communities in Nigeria to use public-issue conflicts as an opportunity to collaboratively explore topics, better understand the issues, and consider alternative solutions. The paper provides an overview of the concept of PIE, the process of public policy education and how PIE helps communities involved in public-issue disputes to reach agreements. Furthermore, the paper identifies (1) roles extension professionals in Nigeria should play in PIE; (2) principles they should observe to successfully impart policy education; (3) ways for evaluating the success of PIE; and (4) institutional requirements for involvement of extension professionals in PIE in Nigeria. The paper concludes that involvement of extension professionals in PIE can only be possible when the institutional environment of extension agencies in the country gives it a worthy support. The extension professionals also will require training on the principles and process of PIE and the ability to practically apply skills so acquired for them to effectively impart public policy education.
\end{abstract}

\section{Introduction}

The need to redefine the purpose and function of extension has recently been acknowledged. Haug (1999) suggests that the role of extension professionals may have to change from 'farmer services' to public policy and education, and should address the need for regulation-enforcement activities and specialized services. Murray (1999) similarly notes that extension's emphasis has shifted from individual profitability and survival to larger societal concerns. Pannel and Marsh (2000) also suggest that this shift is evoking big changes in the types of extension, consistent with the move towards government provision of public goods. In fact, extension in high-income countries is already providing information and education services in urban areas, extending beyond agriculture and rural development alone. Conceiving of extension purely as an agricultural production, rather than an educational service is thus short-sighted and limited (FAO, 2001).

Based on the foregoing arguments, it is conceived here that public issues education (PIE) and management of conflicts are new societal concerns in Nigeria that extension professionals should give attention to. The instability that prevails in the country due to frequent ethnic, religious, and political skirmishes and insensitive public policies underpins the need for her extension professionals to delve into PIE and conflict resolution. The fact that Nigeria was once rated among World's 10 most violent and vulnerable nations by World Vision, a U.S.-based international aid organisation (World Vision, 1999) underscores the need for extension professionals to delve into the issue of how to effectively manage the conflicts persisting in the country. 
Extension needs to delve into public issues and conflict particularly in view of the fact that extension professionals are the workers who have the most frequent and direct contact with people particularly in rural areas of Nigeria. Thus, Nigeria's extension services, by their very mandate and character, should learn to deal with traditional, mostly illiterate rural households, in order to provide them with technical advice not only on agricultural technologies but also on some current issues.

Some possible issues of interest to the Nigerian public that extension professionals could help them to resolve collaboratively include: the Niger Delta crisis, the incessant ethnic/religious conflicts in Jos and other parts of northern Nigeria, the electoral crises, the polio immunization controversy, the on-shore/offshore bill, the introduction of fuel tax, settling of white Zimbabwean farmers in Nigeria, privatisation of public corporations and services, HIV/AIDS, the Afghanistan and Iraqi crises, natural resource disputes between farmers and Fulani herdsmen, to mention just a few. Many of these and other public issues have generated severe controversies in Nigeria that have often resulted into violence (WSWS, 2001; BBC, 2003; IRIN, 2002, 2003; IPS, 2004). If extension professionals can employ PIE to educate the Nigerian public on these and other thorny public issues and to help them resolve them cooperatively, the incidence of conflicts and instability usually associated with people's reaction to the issues could be minimised or avoided completely. However, in order for the extension professionals to determine what their role might be in resolving policy conflicts, they first need to understand the unique characteristics of public issues and the steps of the public policy process (Anon, 1993).

\section{The Concept of Public Issues Education}

A public issue is a topic of concern to a broad community, which often generates controversy due to the differing views, values, and interests which people hold about the issue. Public issues usually prompt public choices - to change policies or preserve the status quo. PIE is an extension educational activity that emphasizes knowledge-based decision-making and is applied to issues of broad concern. It involves educational programmes that have the objective of enhancing the society's capacity to understand and address issues of widespread concern. The principal objective is to help citizens in a democracy to educate themselves so that they can make better-informed policy choices (Danielson and Perrin, undated, ECOP, 1992). Because PIE programmes are designed for issues of conflict, the programmes usually incorporate a variety of techniques including those used in public policy education and public dispute resolution. Incorporating PIE into policy making allows communities to use the conflict as an opportunity to explore topics, better understand the issues, and consider alternate solutions. The purpose of PIE is to help people move from their positions (what they say they want) to their interests (their underlying reason for concern) so they may communicate clearly.

There are a number of models of PIE that extension professionals in Nigeria may find useful. One of them is the public policy education process that focuses on alternatives and consequences. It has evolved over a period of years as a result of a pioneer group of extension workers in the U.S. struggling with various client groups to help them deal with a variety of public problems (WRDC, 1993). Policy education is cyclic and the cycle begins with an issue that is perceived as a problem in the community (e.g. privatization of public corporations and services, petroleum tax, 
polio immunisation or the on-shore/off-shore bill in Nigeria) that needs to be addressed. In an effective policy-making process, people become involved, consider alternative solutions and consequences, choose a policy through one process or another: by public vote, by legislation, or by agency decision, and carry the policy out. Conflict is often involved in making a policy to address the issue because people who are committed to the issue may hold multiple perceptions, values and beliefs, which also need to be understood and considered in making decisions. The final step in the policy education cycle is to evaluate the policy, which may begin the cycle over again. PIE processes may be used during some or all of the steps of the cycle (Danielson and Perrin, 2000; WRDC, 1993).

\section{How PIE helps communities to reach agreements}

PIE provides a setting for people involved in public-issue disputes to reach mutually acceptable solutions by communicating productively and effectively. The PIE process allows communities to focus more effectively on the resolution of public issues by incorporating the following techniques (Danielson and Perrin, 2000):

1. Citizen-participation activities that are designed to bring citizens together with representatives of public and private organizations to make public choices.

2. Interest-based negotiations that emphasizes the awareness of one's own/other parties' interests or why they support a position, rather than the position or the ideal that they want. This allows the invention of new alternatives that satisfy mutual interests.

3. Consensus building, which attempts to make decisions that all members of the group can support. This method encourages group members to educate one another, to generate multiple options, and to select one that satisfy mutual interests.

\section{Resolving public policy disputes}

Conflict is an essential element in the public policy process. It is often involved in making a policy to address an issue because people who are committed to the issue may hold multiple perceptions, values and beliefs, which also need to be understood and considered in making decisions. Conflict is an expressed difference between at least two interdependent parties who perceive incompatible goals, scarce resources, or interference from another party in achieving their goals (Bauer and Watt, 1990). From this definition, the key to resolving conflict rests on the parties' willingness to clearly communicate their perceptions to each other, and their readiness to modify those perceptions when additional data so warrant.

Through conflict the need for improved public policies can be recognised and new policies can be developed that respond to those needs. Conflict can be an opportunity for people and communities to learn, grow, and change in positive directions (Anon, 1993). Extension professionals serving as educators in the public policy process have a special challenge dealing with conflict, especially relating to contentious environmental, political, or tribal/religious issues. While operating in a battleground, extension professionals must remain objective and helpful to all the parties, provide useful and unbiased information, and avoid advocating for any of the parties (WRDC, 1993). Some policy educators have developed skills that will enable policy educators to become involved in negotiation and conflict resolution processes with adversarial groups (Fiske 1991; Patton, 2001; Corp, 2002). The skills are, 
however, dependent upon one's ability first, to recognise conflict, and then determine how it is to be addressed.

\section{Role of extension professionals in PIE}

Extension professionals in Nigeria may play many key roles in PIE. These roles involve content (information provider and technical adviser) and process (convener, facilitator, programme developer, mediator) roles. In content roles, the extension professionals are to provide information and help interpret it. As information providers, they should share research-based facts while as technical advisors, they are expected to help stakeholders sift through the facts and interpret what the facts mean in different contexts. In process roles, the extension professional should help parties to interact productively.

- As conveners, they should seek to draw the various stakeholders into a collaborative problem-solving venture. Collaborative planning is a process in which parties to a dispute agree to work together in anticipation of a conflict, and plan ways to avoid the conflict (Pendzich, 1994 and Anderson et al., 1996 cited in Cousins, 1996).

- As facilitators, they also help choose the meeting ground and format, set the ground rules, focus attention on the decision-making process, and use consensus-seeking techniques. Facilitation is the assistance of a neutral third party in running a meeting and helping make it productive; this can involve assisting in developing an agenda, keeping participants on tract, and in ensuring that all parties have an equal voice (Pendzich, 1994 and Anderson et al., 1996 cited in Cousins, 1996). As either conveners or facilitators, extension professionals may thus work with a coalition of interested parties, establishing goals and procedures through shared decision-making.

- As programme developers, they should help develop long-range educational programmes and set short-range actions to implement the programmes.

- As mediators, they should work with the disputing parties individually or collectively to improve their collaborative problem-solving skills. They also may assume a middle position by intervening, interposing, and reconciling differences in attempts to bring about consensus and settlement (Danielson and Perrin, 2000).

The role of the extension professional as policy educators therefore changes from "expert" to "supporter" when the public policy education model is applied to conflict resolution. The educator is not the direct provider of information and analysis, does not identify the alternatives, does not examine the expected consequences and does not describe the decision process. Instead, the educator becomes the facilitator in teaching new behaviour and managing a collaborative negotiation process that the participants follow to educate themselves, define and analyse the problem, search for alternative solutions, reach an agreement and begin implementation (WREP, 1993).

In policy education, the extension professionals should provide information and analysis and/or facilitate a process to help people understand the issue, identify alternatives, examine the expected consequences and describe the decision process. Extension professionals in Nigeria, thus, have a special challenge in providing useful and unbiased information without taking sides. They must deal with facts, which are verifiable statements; myths, which are what people perceive to be 
true; and values, which are standards of personal preference. The resolution of public issues involves value judgements that generate conflicts. In this context, extension professionals must focus on replacing myths with facts and on creating respect for different values. They, also, should help people to clarify and understand the implications of their values (Danielson and Perrin, 2000).

There are, however, several important principles the policy educator should address to be effective (WREP, 1993; Danielson and Perrin, undated):

1. Be sure you know where your audience is in the issue cycle. If you are describing alternatives and consequences for people who have not yet clearly defined or understood the issue, their effort will be wasted and confusing. Remember that different groups will be at different steps.

2. Never advocate a particular outcome or solution. It will compromise your credibility as an educator both now and in the future. It is a known fact that educators are people too, and have their own values and beliefs that prevent them from being completely objective and neutral. The challenge for extension professionals is to strengthen advocates on all sides of the issue.

3. Do not describe the consequences of alternatives as advantages or disadvantages or pros and cons. What is a pro for one group is very likely to be a con for someone else.

4. The solution has to be implemented and there is always the possibility of faulty implementation, because the consequences may turn out to be different than expected. The evaluation period should show if the solution works to satisfy the parties involved. In these last two steps the policy educator can again play an important role.

5. The policy educator does not participate directly in the decision on choice of alternative except to facilitate the understanding and participation of others in the decision-making process.

6. Be alert to recognize a teachable moment. This typically occurs when potentially affected people or groups are concerned enough about an issue that they are receptive to educational information. If, however, people have become so fervently wedded to inflexible positions that they are unable to accept additional information and analysis, it is unlikely an educational programme will be successful (Sachs et al. cited in WREP, 1993). This may, however, be a point where the collaborative conflict resolution model can be applied.

7. If few citizens seem to care about an important public issue, the policy educator should target and gather feedback from those citizens who do express an interest. He should then educate others on how the issue affects their community. This may lead to better understanding of the issues and provides information that could serve as solid basis for decision-making that incorporates stakeholder concerns.

8. Check out your own personal biases. You should only work on an issue if you can suspend any biases about it.

9. Don't try to answer technical questions outside your area of expertise - direct citizens to the appropriate source.

10. Understand that potentially explosive public issues require constant monitoring and flexibility in your approach. 
11. Be prepared to work with your group to reach an agreement on types and sources of information that will be used to evaluate the problem and options for solution.

12. Preparation is a key to success in PIE, particularly when the issue is controversial and people are in conflict. Good preparation may entail talking to stakeholders before bringing them together to learn about the issues, and identify people and organizations to be involved in finding solutions.

13. Once a group has arrived at a solution to a problem, be sure to lay the groundwork so the solutions get carried out.

\section{Outcome of Successful PIE}

Some possible outcomes of successful PIE include:

- Better understanding of issues

- Collaborative efforts to address issues

- Expanded options for addressing the issue

- A more thorough analysis of impacts

- Public choices that are more effective, sustainable, and fair

- Long run benefits that include greater competence among leaders and public representatives, more networks of collaborators, and enhanced community and organization ability to address issues (Dale, 1993 cited in Danielson and Perrin, 2000).

\section{Institutional requirements for involvement of extension professionals in PIE}

Extension professionals can only engage themselves in PIE if it falls within the mandates of organisations they serve. Unfortunately, many extension agencies in Nigeria are yet to include PIE among their mandates. However, because of the high potentials in Nigeria for many public issues to cause controversy, it is necessary for extension organisations to explicitly incorporate PIE into their programmes. Training is also required to acquaint extension professionals with the principles, process and practice of PIE. Integrating PIE into curricula of extension programmes in Nigerian universities and related training institutions may be one step along this direction. In turn, extension professionals must plan and execute PIE programmes that are balanced, that are based upon scientifically derived information, and that facilitate collaborative problem solving (Danielson and Perrin, 2000).

The administrations of extension organisations in Nigeria also need to recognise that PIE may place extension professionals in controversial positions particularly when they are handling contentious issues. A policy statement from the North Carolina Cooperative Extension Service as cited in Danielson and Perrin (2000) particularly observe that no PIE programme is totally risk-free to the Extension professional, but the support or involvement of advisory groups or supervisors will minimise the risk. The commitment of extension administrations in Nigeria to PIE can be in 1) their support for appropriate in-service training and study leave opportunities for extension professionals pursuing careers in PIE; 2) the development of educational materials and fostering of linkages and informationsharing with other agencies and groups; 3 ) the acquisition and allocation of additional resources where possible; and 4) the recognition and rewarding of those individuals who conduct PIE programmes.

\section{Conclusion}


The need for extension professionals in Nigeria to venture into PIE and conflict resolution cannot be over-emphasised because (1) Nigeria operates a "democracy" that ideally should provide a conducive atmosphere for imparting public policy education; (2) the potential for public issues in the country to degenerate into controversies and violent conflicts is very high particularly when the issues affect sensitive matters such as religion, ethnicity, sharing of resources, etc. . Incorporating PIE into policy making will allow communities in Nigeria to use the conflict as an opportunity to explore topics, better understand the issues, and consider alternate solutions.

However, involvement of extension professionals in Nigeria in PIE can only be possible when the institutional environment of extension agencies in the country gives it a worthy support. The extension professionals also will require training on the principles and process of PIE and the ability to practically apply skills so acquired for them to effectively impart public policy education. It is therefore recommended that Extension institutions should make effort to mainstream PIE into their purview and also provide their staff with the necessary training to practice PIE on the field.

\section{References}

Bauer, L. and P.K. Watt (1990). Dispute resolution: a handbook for land use planners and resource managers. Prepared for the Oregon Department of Land Conservation and Development. University of Oregon Bureau of Governmental Research and Service, November.

BBC (2003). Violence brings curfew in Niger Delta. BBC News World Edition, 17 August.

Corp, M.K. (2002). Conflict-laden issues: a learning opportunity. Journal of Extension, Vol. 40, No. 1.

Cousins, B. (1996). Conflict management for multiple resource users in pastoral and agro-pastoral contexts. IDS Bulletin, Vol. 27, No. 3, p. 49.

Danielson, L. and Perrin, C. (2000). Extension's role in public issues education and dispute resolution, North Carolina Cooperative Extension Service, North Carolina State University, USA

http://www.ces.ncsu.edu/depts/agecon/PIE/newpie/public issues ed/pdf/PIE fact sheet2000.pdf.

Extension Committee on Organization and Policy (1992). Public issues education. The cooperative extension system's role in addressing Public Issues. ECOP, Washington, DC: Extension Service, USDA.

FAO (2001). Agricultural and rural extension worldwide: options for institutional reform in the developing countries.

Fiske, E.P. (1991). Controversial issues as opportunities: extension effectiveness in resolving environmental disputes." Journal of Extension, Fall Issue.

Haug, R. (1999). Some leading issues in international agricultural extension, a literature review, Journal of Agricultural Education and Extension, vol. 5, no. 4.

IPS (2004). Labor-Nigeria: union leaders call for strike over fuel tax. Inter Press Service News Agency, January 10.

IRIN News (2002). Nigeria: dozens reported dead in clashes between farmers, herders, January 8, IRIN News.org.

IRIN (2003). Nigeria: parliament to discuss polio vaccine controversy. IRIN News.org 
Murray, M. (1999). A contrast of the Australian and California extension and technology transfer processes, Journal of Extension, Vol. 37, No. 2.

Patton, D.B. (2001). Public issues education: exploring extension's role. Journal of Extension, Vol. 39, No. 4.

World Vision (1999). Sri Lanka, Montenegro \& African 'arc of conflict' among top 10 'global hot spots' for 2000. World Vision, United States, 12 December.

WRDC (1993). Public policy education - its role in community change. A Western Regional Extension Publication, WREP 23, Western Rural Development Centre, Utah State University, Logan, USA.

WSWS (2001). Protest against Afghan bombings sparks ethnic conflict in Nigeria. World Socialist Website, 20 October. 